\title{
Quantitative Assay Using Recombinant Human Islet Glutamic Acid Decarboxylase (GAD65) Shows That 64K Autoantibody Positivity at Onset Predicts Diabetes Type
}

\author{
William A. Hagopian, * Allan E. Karlsen, * A Anders Gottsäter, ${ }^{5}$ Mona Landin-Olsson," Catherine E. Grubin, * \\ Göran Sundkvist, Jacob S. Petersen, " Esper Boel, "Thomas Dyrberg," and Åke Lernmark * \\ * Department of Medicine, University of Washington, Seattle, Washington 98195; Department of Medicine, University of Lund, Malmö \\ General Hospital, S21401 Malmö, Sweden; "Department of Medicine, University of Lund, University Hospital, S22185 Lund, Sweden; \\ ${ }^{\ddagger}$ Hagedorn Research Laboratory, DK2820 Gentofte, Denmark; and"Novo Nordisk A/S, \\ Bioscience and Diabetes, DK2880 Bagsvard, Denmark
}

\begin{abstract}
At and before onset, most insulin-dependent diabetics (IDDM) have islet GAD65 autoantibodies (GAD65Ab). Since IDDM also occurs in older patients where non-insulin-dependent diabetes is common, we studied GAD65Ab at onset to classify diabetes type. Our quantitative immunoprecipitation assay uses recombinant human islet GAD65 stably expressed in hamster fibroblasts. Electrophoretic mobility was identical to native islet GAD65. Like native antigen, recombinant GAD65 migrated as two bands during electrophoresis, but converted to one under stronger reduction. Immunoprecipitation was linear with respect to antibody or antigen concentration. In $120 \mathrm{popu}-$ lation-based diabetic patients of all ages grouped by treatment at onset and after $18 \mathrm{mo}, \mathrm{GAD65Ab}$ were present in $70 \%$ on insulin $(n=37), 10 \%$ on oral agent $(n=62, P<0.0001), 69 \%$ changing from oral agent to insulin $(n=16, P<0.001)$, and 1 of 33 controls. $65 \%$ with GAD65Ab, versus $8 \%$ without, changed from oral agent to insulin $(P<0.01)$. The GAD65Ab quantitative index was remarkably stable, and only 2 of 32 patients changed antibody status during follow-up. Concordance between GAD65Ab and islet cell antibodies was 93\%. Quantitative correlation was approximate but significant. This highly sensitive, quantitative, high capacity assay for GAD65Ab reveals treatment requirements better than clinical criteria, perhaps guiding immunomodulatory therapy. (J. Clin. Invest. 1993.91:368-374.) Key words: islet cell antibodies • autoimmunity • immunoprecipitation • autoantigen • BHK fibroblasts
\end{abstract}

\section{Introduction}

Increasingly refined measurements of beta cell-directed autoantibody markers have led to their increased importance, in combination with HLA typing and tests of insulin secretion, in studying the pathogenesis of insulin-dependent diabetes

Address reprint requests to Dr. William A. Hagopian, R. H. Williams Laboratory, Department of Medicine, RG-20, University of Washington, Seattle, WA 98195.

Received for publication 20 May 1992 and in revised form 5 October 1992.

J. Clin. Invest.

(C) The American Society for Clinical Investigation, Inc.

0021-9738/93/01/0368/07 \$2.00

Volume 91, January 1993, 368-374
(IDDM). ${ }^{1}$ Autoantibodies to an islet protein of $M_{\mathrm{r}} 64,000$ $(64 \mathrm{~K})$, first described more than a decade ago $(1,2)$, are present in most newly diagnosed IDDM patients and prediabetic first-degree relatives $(3,4)$, may precede other antibody markers $(4,5)$, are present in animal models of $\operatorname{IDDM}(6,7)$, and may have greater sensitivity, specificity, and predictive value for human IDDM than other established markers $(3,5$, 8 ). The true utility of $64 \mathrm{~K}$ antibody measurement is unknown, however, since islet-based immunoprecipitation assays are expensive and laborious, preventing completion of large studies. Identification of $64 \mathrm{~K}$ as the smaller isoform of glutamic acid decarboxylase (9) has facilitated strategies to overcome these limitations.

GAD has multiple isoforms encoded by different genes (for review, see references 10 and 11 ). Although rat islets have significant amounts of at least two isoforms $(12,13)$, both Northern (14) and Western (15) blotting have shown that a single isoform, GAD65, is expressed in human islets and is the $64 \mathrm{~K}$ protein $(9,15)$. We recently cloned the GAD2 gene from human islets (14), and stable expression of the transfected gene in baby hamster kidney (BHK) fibroblasts has allowed development of a large-scale GAD65 immunoprecipitation assay.

Since effective autoimmune intervention strategies will probably exist soon, identification of autoimmune diabetes before clinical onset is critically important. Accurate classification of diabetes type at onset will at least guide glucoregulatory therapy. More importantly, it may allow early application of immunointervention strategies in patients otherwise not considered to have IDDM. Using a quantitative assay based on recombinant human islet GAD65, we studied whether GAD65Ab accurately anticipates clinical course, relative to conventional tests, in a population-based sample of new-onset diabetics.

\section{Methods}

BHK K77.3 fibroblasts. A BHK fibroblast line was derived from American Type Culture Collection \#CRL 1632 (BHK tk- ts 13) cells (16) by transfection with human islet GAD2 cDNA from plasmids pHIG11

1. Abbreviations used in this paper: BHK, baby hamster kidney; BMI, body mass index; GAD, glutamic acid decarboxylase; ICA, islet cell antibodies; IDDM, insulin-dependent diabetes; ins, insulin; JDF, Juvenile Diabetes Foundation; $\beta \mathrm{ME}, \beta$-mercaptoethanol; NC, negative control healthy serum; NIDDM, non-insulin-dependent diabetes: OHA, oral hypoglycemic agent; PAS, protein A-Sepharose; PC, positive control serum. 
and pHIG1.9 (14) cloned into the mammalian expression vector Zem $219 \mathrm{~b}$ (17), which also expresses dihydrofolate reductase. A cell line (BHK-K77.3) with stable intracellular production of recombinant human islet GAD65 was selected in DME containing 10\% FCS (Gibco Laboratories, Grand Island, NY) and methotrexate. Immunocytochemistry using GAD-6 mouse monoclonal antibody (18) showed that BHK K77.3 fibroblasts express GAD65 in the perinuclear region, and rarely, throughout the cell (15). Confluent cells biosynthetically labeled for $12 \mathrm{~h}$ with $\left[{ }^{35} \mathrm{~S}\right.$ ] methionine (Amersham Corp., Arlington Heights, IL) were fractionated as described for islets $(5,19)$. GAD65 was present in both cytosolic and membrane detergent phases from transfected BHK fibroblasts, but not in cytosolic or membrane aqueous phases (data not shown). $1.5 \%$ of the radioactivity in the transfected BHK cell membrane detergent phase was precipitable as GAD65, representing $0.4 \%$ of total cellular radioactivity. Corresponding values for nontransfected BHK cells were 0.06 and $0.01 \%$ of total radioactivity, respectively.

Human islet isolation. Human islets were isolated, using collagenase digestion and Ficoll density gradient purification, from pancreata obtained with proper consent but for which a matched recipient was not found. Biosynthetic radiolabeling proceeded as above.

Immunoprecipitation assay for GAD65 autoantibodies. The membrane detergent phases of radiolabeled human islets and of radiolabeled BHK K77.3 fibroblasts were separately preincubated at $4^{\circ} \mathrm{C}$ for $12 \mathrm{~h}$ with normal human serum not subsequently used in the assay. Immunoglobulin was cleared using excess protein A-Sepharose (PAS; Zymed Laboratories Inc., South San Francisco, CA), and preclearing was repeated. The final supernatant was diluted in $10 \mathrm{mM}$ Hepes buffer containing $0.25 \%(\mathrm{wt} / \mathrm{vol}) \mathrm{BSA}, 0.1 \%(\mathrm{wt} / \mathrm{vol}$ ) aprotinin (Novo, Bagsvœrd, Denmark), 0.1 mM PMSF (Sigma Chemical Co., St. Louis, $\mathrm{MO}$ ), and $150 \mathrm{mM} \mathrm{NaCl}$, at $\mathrm{pH}$ 7.4. For each unknown serum assayed, $\sim 5 \times 10^{5} \mathrm{cpm}$ of BHK-derived antigen mixture in $590 \mu \mathrm{l}$ was separately incubated with $10 \mu \mathrm{l}$ of human serum for $12-16 \mathrm{~h}$ at $4^{\circ} \mathrm{C}$ with mixing. Immune complexes were precipitated with $80 \mu \mathrm{l}$ of $1: 2$ PAS, washed at $4^{\circ} \mathrm{C}$ four times in the above buffer and once with $20 \mathrm{mM}$ Tris, pH 7.5, eluted into $2 \times$ Laemmli buffer $/ 5 \% \beta$-mercaptoethanol ( $\beta$ ME; Eastman, Kodak Co., Rochester, NY), and analyzed by electrophoresis on $7.5 \%$ polyacrylamide gels containing sodium dodecyl sulfate (SDS-PAGE). Gels were treated with Entensify (New England Nuclear, Boston, MA) before fluorography. In some experiments, $\beta \mathrm{ME}$ or DTT concentrations were varied as described. For Fig. $1 B$, a $10 \%$ gel with a 1:200 bisacrylamide-acrylamide ratio (rather than the standard 1:37.5 ratio) was used to better separate GAD65 bands.

Each fluorogram contained ${ }^{14} \mathrm{C}$-labeled molecular weight markers (Amersham Corp.), three control lanes analyzing immunoprecipitations using positive control serum (PC), negative healthy control serum (NC), GAD-6 mouse monoclonal ascites, and up to 19 test sera. The positive control serum was obtained at onset from a diabetic child who is the Juvenile Diabetes Foundation (JDF) world standard for islet cell antibodies (ICA), tests positive for $64 \mathrm{~K}$ antibodies in islet-based assays, and has a moderate GAD65Ab level compared with the range seen in new-onset IDDM patients. GAD-6 monoclonal antibody provides excess antibody binding capacity, and measures the maximum precipitable antigen per individual assay. Bands at $M_{\mathrm{r}} 64,000$ were quantified by laser densitometric scanning as integrated area under each peak (2202 Ultroscan; LKB, Bromma, Sweden) with threshold set at 8 (defining area $<1 \times 10^{6}$ as zero). Raw densitometry data, in arbitrary units measuring integrated area under densitometry curves, varied from 0 to $4.48 \times 10^{7}$ for unknowns, from 0 to $1.9 \times 10^{6}$ for the negative control (zero in seven out of nine films), from $0.4 \times 10^{7}$ to 3.3 $\times 10^{7}$ for the positive diabetic control, and from $3.0 \times 10^{7}$ to $8.9 \times 10^{7}$ for the positive monoclonal control. Gels with film bands exceeding the densitometer sensitivity range were re-exposed for less time and rescanned. In all individual films, the positive diabetic control:negative control ratio was always $>10: 1$, while the positive monoclonal control:negative control ratio was always $>35: 1$. GAD65Ab index was calculated from integrated areas by the formula: index $=$ (unknown - NC)/(PC - NC). Intra- and inter-assay coefficients of variation were 26 and 29\%, respectively. For qualitative results, any index above 0 was considered positive.

Islet cell antibodies. ICA titration data from immunofluorescence assay on human pancreas sections has been published (20). Titration values are converted to JDF units using standard sera (21).

Diabetic patient recruitment and follow-up. Malmö, Sweden had 230,056 inhabitants in 1986. Most new-onset diabetics of all ages in the Malmö area are seen at the Diabetes Care Unit of Malmö General Hospital, but ascertainment was increased even further by recruiting patients from the departments of Medicine, Endocrinology, and Pediatrics at Malmö General Hospital, and from private physicians informed about the study. The 120 patients described here (age range 6-79 yr, mean $37.9 \mathrm{yr}$ ) were selected from 244 consecutive new-onset diabetics who entered the study during the 2-yr period between September 1985 and August 1987 (20). The groups are defined by treatment with insulin (ins) or oral hypoglycemic agent/diet (OHA) at 0 and $18 \mathrm{mo}$ after onset as follows: group 1, ins/ins $(n=37)$; group 2, OHA/OHA ( $n$ $=62)$; group 3 , OHA $/$ ins $(n=16)$; group 4 , ins $/$ OHA $(n=5)$. Group 5 consisted of 33 normal healthy controls from Malmö. From the original 244 patients, all ins/ins, OHA/ins, and ins/OHA patients were tested. All five $\mathrm{OHA} / \mathrm{OHA}$ patients who were ICA positive, as well as 57 additional patients randomly selected from the remaining 188 OHA/OHA patients, were tested. Blood was sampled after an overnight fast as soon as possible, but always within 3 mo of diagnosis and 6 mo of first symptomatic hyperglycemia. Patients were characterized by age, family history, body mass index (BMI), and fasting serum C-peptide, and these data have been described (20). Therapy at $1 \mathrm{wk}$ after diagnosis was defined as initial therapy, and therapy at 18 mo followup and subsequently (range 18-49 mo) was obtained from patient records. In a subset of 48 patients, further samples were drawn 1-2 yr and 2-3 yr later ( 66 total samples; not every patient was sampled at every time point). The study was approved by the ethical committee at the University of Lund, Lund, Sweden.

Statistical methods. Analysis of differences of test criteria between patient groups used the Chi-square method, and the relationship between ICA titer and GAD65Ab index was analyzed by linear regression.

\section{Results}

Parallel immunoprecipitations using human islets and transfected BHK fibroblasts allowed comparison of antigen from the two sources. Fig. $1 A$ shows a fluorogram based on 200 human islets (lane 3 ), or on $4 \times 10^{4} \mathrm{BHK}$ fibroblasts per lane (lanes $I$ and 2). Estimating 1,300 beta cells per islet (22), the amount of immunoprecipitable GAD per BHK cell is well over 10 -fold greater than that per human beta cell. However, electrophoretic mobility of the native (lane 3 ) and recombinant (lane 1) GAD65 is identical. Recombinant GAD-67 (lane 2) is shown for comparison. As previously described for islet-derived 64K $(13,23)$, immunoprecipitated GAD65 from transfected BHK fibroblasts migrated as two bands (termed $\alpha$ and $\beta$ ) on one-dimensional reducing SDS-PAGE (Fig. $1 B$ ). Stronger reducing conditions achieved by increasing $\beta \mathrm{ME}$ from 1 to 5 to $15 \%$ (lanes $1-3$ ) or DTT from 0.05 to 0.2 to 0.5 M (lanes 4-6) appeared to convert recombinant GAD65 to a single band corresponding to the most rapidly migrating $\beta$ species.

The immunoprecipitation assay showed linearity with respect to GAD65Ab amount, over a range from 0.6 to $10 \mu \mathrm{l}$ of a strongly reacting diabetic serum (Fig. 2, lanes 3-7). In these experiments, normal human serum was added to maintain Ig concentration equivalent to $10 \mu \mathrm{l}$ serum. The assay also demonstrated linearity with respect to BHK-derived antigen concentration, over a range of starting radioactivity from $2.5 \times 10^{5}$ to $2 \times 10^{6} \mathrm{cpm}$ (Fig. 2, lanes 9-12), representing specific GAD65 

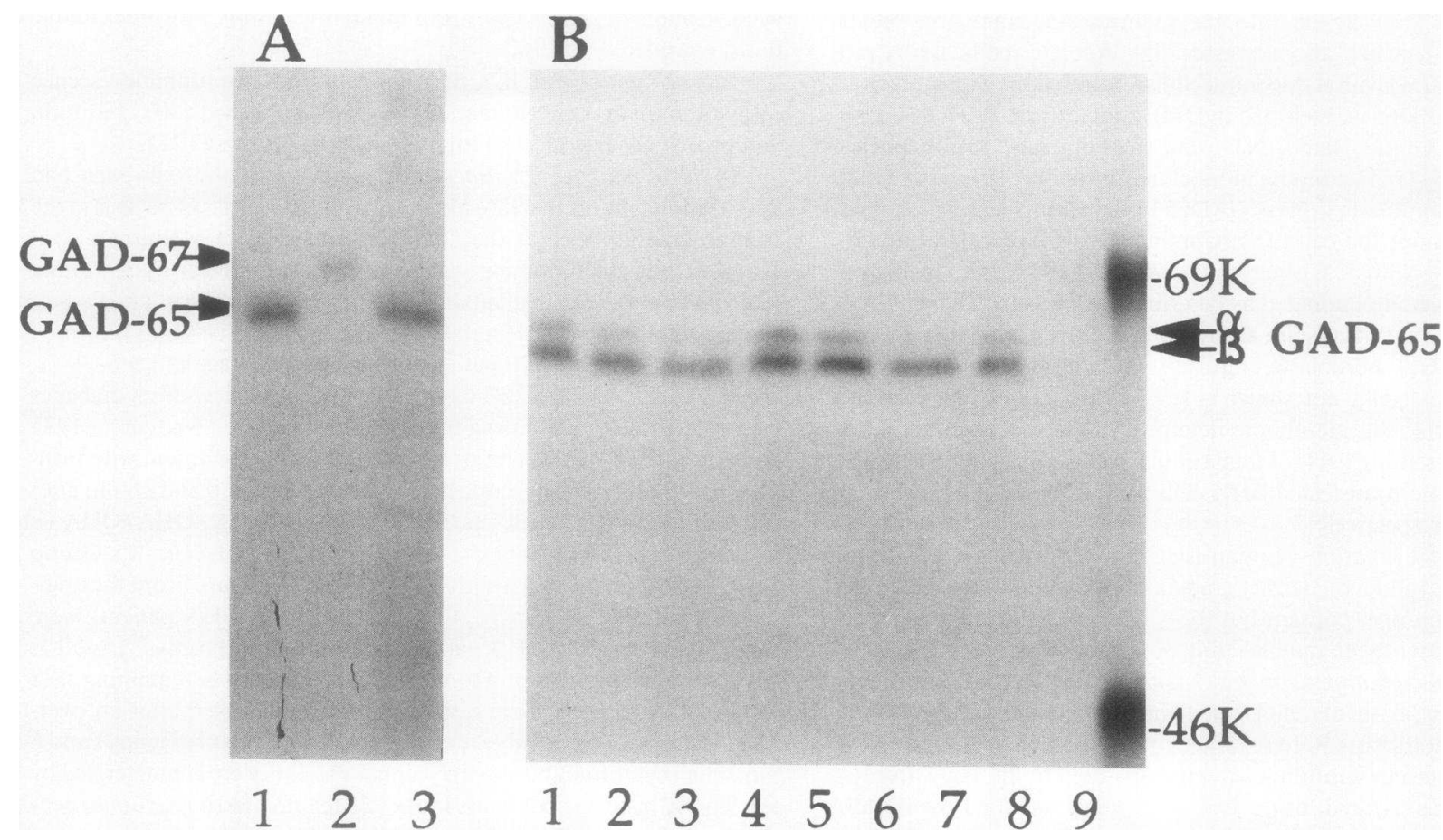

Figure 1. (A) Comparison of immunoprecipitated GAD65 from human islets (lane 3) to recombinant GAD65 from transfected BHK fibroblasts (lane 1). For comparison, GAD-67 from another transfected fibroblast line is also shown (lane 2). Antibodies used were: GAD-6 monoclonal antibody to GAD65 (lanes 1 and 3) and rabbit polyclonal antiserum K2 against GAD-67 (lane 2). (B) Effect of reducing conditions on GAD65 double bands. Recombinant antigen was precipitated with GAD65 specific monoclonal antibody, boiled in sample buffer with increasing amounts of $\beta \mathrm{ME}(1,5$, and $15 \%$ in lanes 1,2 , and 3 , respectively) or DTT $(0.05,0.2$, and $0.5 \mathrm{M}$ in lanes 4,5 , and 6 , respectively) and electrophoresed. Lanes 7 and 8 used 5\% $\beta \mathrm{ME}$ on precipitations using diabetic and healthy control human sera, respectively. The two GAD65 bands are designated $\alpha$ and $\beta$ (13).
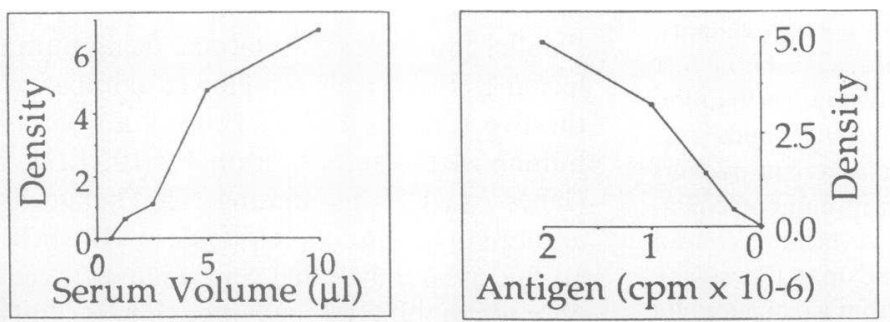

$69 \mathrm{~K}-$
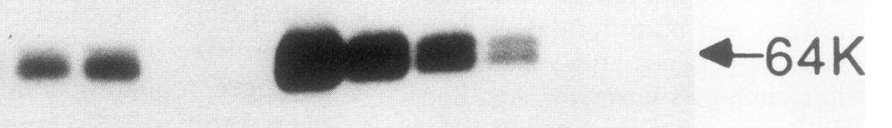

\section{LANE $12 \begin{array}{llllllllllllll} & 2 & 3 & 4 & 5 & 6 & 7 & 8 & 9 & 10 & 11 & 12 & 13 & 14\end{array}$}

Figure 2. Effect of antigen and antibody concentration on the immunoprecipitation assay. (Left) Immunoprecipitations using $0.63,1.25,2.5,5$, and $10 \mu \mathrm{l}$ of one GAD65Ab positive diabetic serum in lanes 3,4 , 5,6 , and 7 , respectively. Lane 2 shows immunoprecipitation using $10 \mu \mathrm{l}$ normal human serum only, and lane $l$ contains radiolabeled molecular weight markers. (Inset) Densitometric scanning of lanes 2-7 plotted versus volume of diabetic serum. Density is given in arbitrary units. (Right) Decreasing amounts of radiolabeled BHK cell membrane detergent extract from 2, 1, 0.5, and

$0.25 \times 10^{6} \mathrm{cpm}$ in lanes $9,10,11$, and 12 , respectively, were precipitated with $10 \mu$ l of strongly positive diabetic serum. Lane 14 uses $10 \mu 1$ healthy control serum. Lane 13 shows reprecipitated supernatant from the lane 10 immunoprecipitation. (Inset) Densitometric scanning of lanes $9-13$ plotted versus starting antigen amount. 

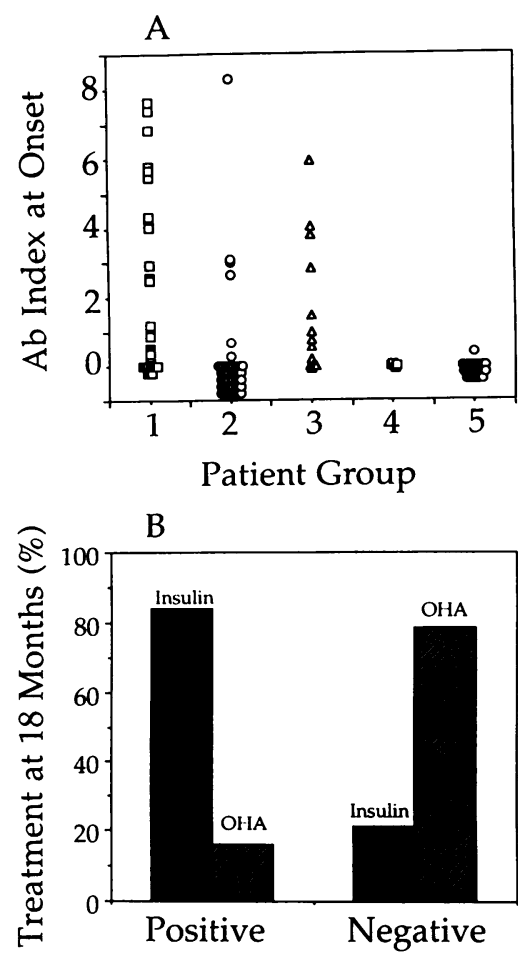

$\mathrm{Ab}$ status at Onset
Figure 3. Relationship of GAD autoantibodies to treatment regimen. (A) Quantitative GAD65 Ab indices at onset versus patient treatment type at 0 and 18 mo after onset: group 1 , ins/ins $(n=37)$; group 2, OHA/OHA ( $n$ $=62$ ); group 3 , OHA / ins $(n=16)$; group 4 , ins/OHA $(n=5)$; group 5, healthy matched controls $(n$ = 33). Qualitative positivity in the five groups was $70,10,69,20$, and $3 \%$, respectively. $(B)$ Treatment type at 18 mo follow-up compared with GAD antibody positivity at onset.

radioactivity of $\sim 4 \times 10^{3}-3 \times 10^{4} \mathrm{cpm}$, from $\sim 15,000-$ 120,000 fibroblasts, respectively. Lane 13 shows reprecipitation of supernatant from the immunoprecipitation of lane 9 , illustrating that the first reaction quantitatively precipitated all antigen.

Using the GAD65Ab assay, we analyzed sera drawn at onset from the population-based sample of 120 diabetic patients grouped by treatment type at onset and 18 mo later. The quantitative GAD65Ab index derived by densitometric scanning of fluorograms is shown for samples drawn at onset from each of the four diabetic treatment groups and for the healthy control group in Fig. $3 \mathrm{~A}$. There are clear differences in the GAD65Ab index between these groups, with mean index \pm SEM being $1.77 \pm 0.41,0.29 \pm 0.15,1.35 \pm 0.47,0.012 \pm 0.013$, and 0.013 \pm 0.013 for the five groups, respectively. As shown in Fig. $3 B$,

GAD65Ab at onset was strongly associated with insulin treatment 18 mo later $\left(\chi^{2}=45 ; P<0.0001\right)$. For example, 11 of 17 patients $(65 \%)$ initially treated with oral agent, but with GAD65Ab at onset, required insulin treatment by $18 \mathrm{mo}$, while only 5 of 61 patients $(8 \%)$ initially on oral agents, but without GAD65Ab at onset, later required insulin therapy $\left(\chi^{2}\right.$ $=26.0 ; P<0.01)$. By 36 mo after onset, three more GAD65Ab positive patients ( total 14 of $17,82 \%$ ) required exogenous insulin.

Table I shows the prevalence of several clinical parameters (age, BMI, and family history), secretory function (fasting Cpeptide), and antibody markers (ICA and GAD65Ab) in the four diabetic and one control groups. This table also estimates the ability of each of these criteria to detect group 3 patients among those in groups 2 and 3, and thus to predict insulin requirement in patients initially diagnosed with non-insulindependent diabetes (NIDDM). Although BMI, and especially C-peptide, also differ significantly between those requiring and not requiring insulin therapy, the ICA and GAD65Ab tests clearly have the best predictive value. In the current assay, GAD65Ab are as good as, but not better than, ICA for this prediction.

In addition to serum obtained at onset, 48 patients had sera drawn once or twice more during the next $3 \mathrm{yr}$. The percentage of GADAb positivity is summarized for each patient group and time interval in Fig. $4 \mathrm{~A}$. Qualitative GAD65Ab positivity in this subset was generally similar to that found in the onset samples from all patients (see text and Fig. $3 A$ ), although slightly higher in group 2 due to small sample size. These data are shown primarily to establish the stability of GAD65Ab prevalence over time. In fact, 31 of 33 patients tested at multiple time points $(94 \%)$ were always positive or always negative. Each line in Fig. $4 \mathrm{~B}$ shows quantitative GAD65Ab levels in serial samples from the same patient during the $3 \mathrm{yr}$ after onset. Although some patients lost or gained autoantibody levels over time, most had remarkably stable GAD65Ab indices throughout the study.

Comparison of serum samples positive for GAD65Ab with those with ICA $\geq 2$ JDF units ( Table II ) reveals extensive qualitative concordance $(93 \%)$ between the two tests. The few discordant sera are mostly GAD65Ab positive and ICA negative ( 7 of $153,5 \%$ ), perhaps due to the high sensitivity of the GAD immunoprecipitation assay, or in cases of high GADAb index,

Table I. Prevalence (Percent) of Clinical Parameters Such as Age, BMI, and Family History (FH); of Secretory Function Measured by Fasting C Peptide (Cpep); and of Antibody Markers Such as ICA and GAD65Ab, in the Four Diabetic and One Control Groups

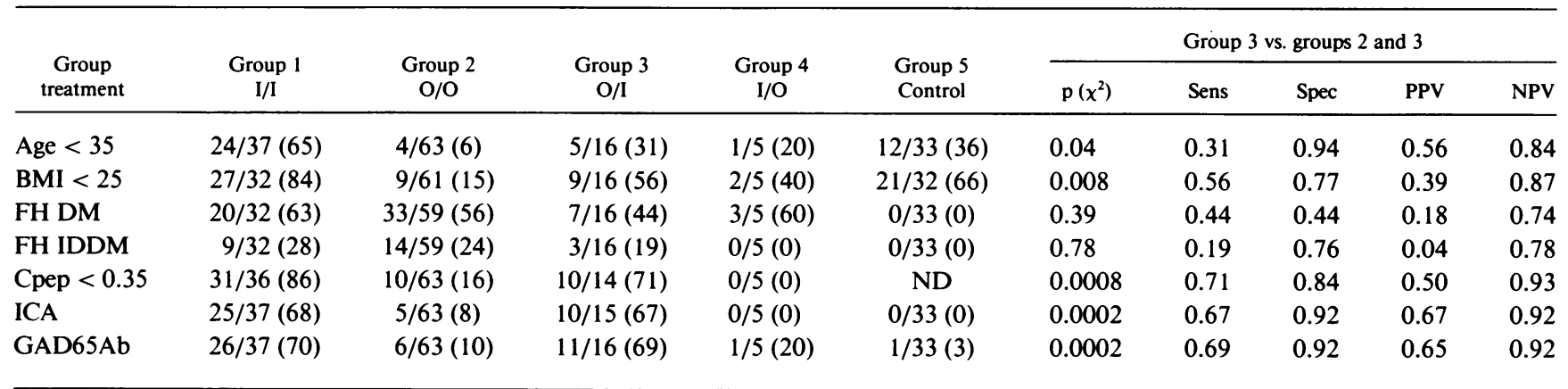

Prediction of progression to insulin therapy (group 3) in patients initially diagnosed as NIDDM (groups 2 and 3). The observed prevalence of IDDM among newly diagnosed NIDDM patients was 16 of $181(9 \%) . \chi^{2}$, Chi square test; Sens, sensitivity; Spec, specificity; PPV, positive predictive value; NPV, negative predictive value. 

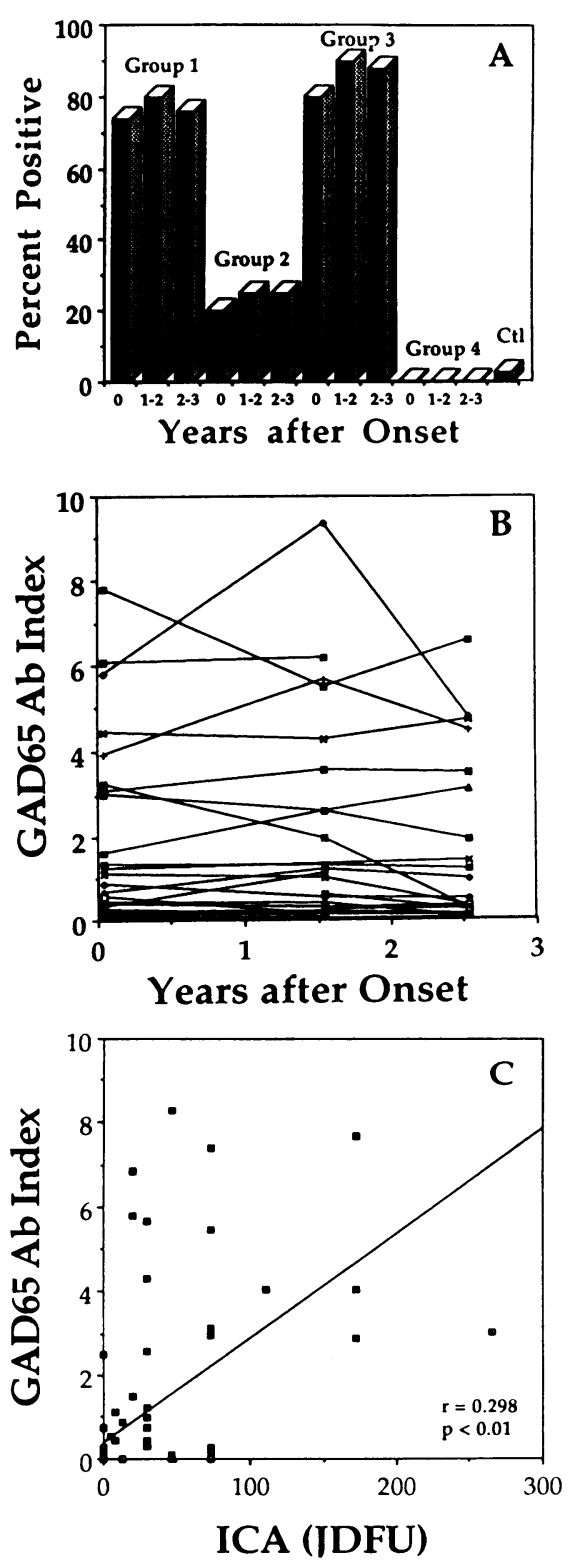

Figure 4. (A) Qualitative GAD65 antibody positivity plotted by serum sampling time after onset and by treatment group, in a subset of patients from whom multiple samples were drawn. Not every patient is sampled during every time interval. Group 1, ins/ins ( 55 samples from 23 patients); group 2, OHA/OHA ( 18 samples from 12 patients); group 3, OHA/ins ( 28 samples from 11 patients); group 4 , ins/OHA ( 6 samples from 2 patients); group 5, healthy controls from the same population ( $\mathrm{Ctl}, n=33$ ). (B) Quantitative GAD65Ab index at onset versus index 1-2 and 2-3 yr later for the 33 diabetics in $A$. Each line represents a single patient followed over time. $(C)$ GAD65Ab index versus ICA titer in JDF units $(r=0.298, P<0.01)$. 119 data pairs were analyzed, but for graphical detail the five with highest titers are not shown.

to variable expression of some GAD epitopes in standard ICA tissue sections. Other ICA antigens have been described (2426 ), and it is not surprising that at least some sera ( 3 of 153 , $2 \%)$ are ICA positive and GAD65Ab negative. However, as shown in Fig. $4 \mathrm{C}$, plotting quantitative GAD65Ab index at onset (range $0-9.23$ ) versus ICA titer at onset (range $0-5,520$ JDF units) reveals limited but significant correlation between the two tests $(r=0.298, P<0.01)$.

\section{Discussion}

We show here that GAD65 autoantibody status at onset of diabetes is a good predictor of subsequent clinical course. These antibodies can differentiate, in patients clinically diagnosed as NIDDM, a subset that has active autoimmunity and often progresses to insulin requirement. This study reveals that 18 of 191 , or $\sim 9 \%$, of these patients have markers of autoimmunity. Although BMI and especially C-peptide also differ significantly between those with and without autoimmunity, the ICA and GAD65Ab tests clearly have the best predictive value.

IDDM occurs more frequently in families with a strong history of NIDDM than in the general population (27). This reflects the inability of conventional clinical criteria to separate them, perhaps because the two pathophysiologic mechanisms can coexist. Beta cell-directed autoimmunity may contribute to the insulin insufficiency present in patients classified as NIDDM (28), and insulin resistance may unmask latent IDDM. Not all autoimmune patients need progress to insulin therapy, since there is evidence in both first-degree relatives of IDDM patients and in NIDDM patients that autoimmunity may stably remit after partial destruction of beta cell mass $(4,29)$.

Heterogeneity of diabetes in older individuals has long been appreciated. While in the simplest analysis clinicians noted thin older patients with new-onset diabetes who often had ketonuria and eventually required exogenous insulin, studies measuring body mass ( 30 ) and endogenous insulin/C-peptide secretion (31) objectively separated patients into groups with different characteristics. Furthermore, insulin autoantibody (32) or islet cell antibody (29) testing in NIDDM indicated beta cell-directed autoimmunity, and successfully revealed patients requiring insulin treatment $(20)$ and having low endogenous insulin secretion (33). Epidemiologic evidence measuring cumulative incidence of IDDM reveals that although peak incidence is at ages $12-14 \mathrm{yr}, \sim 30 \%$ of autoimmune diabetes manifests after age 35 (34). Estimating $\sim 10$-fold greater prevalence of maturity-onset versus juvenile diabetes, and estimating that $9 \%$ of maturity-onset patients have autoimmune markers as in this study, we again calculate that almost as much autoimmune diabetes occurs in maturity-onset patients as in younger ones. That these individuals often do well on diet or oral agents for years before requiring insulin suggests that the autoimmune process may occur more slowly in older patients. At presentation, these patients may still have enough beta cell mass to maintain normoglycemia if immunointervention can effectively halt further loss, and they should be considered for immunointervention trials.

Immunoreactivity of islet GAD is easily lost during islet isolation due to high levels of proteolytic enzymes, and during electrophoresis or electroblotting presumably due to denaturation. Our methods improve assay accuracy by utilizing more antigen than islet-based assays, allowing less contaminating proteases, labeling antigen in a way not altering native structure, and avoiding solid-phase steps prone to denaturation. Most importantly, since antigen is available in larger amounts than obtainable from islets, GAD65Ab can be measured in many hundreds of sera (219 in this study) to assess the pathophysiologic role of GAD65 Ab in autoimmune diabetes, to evaluate screening strategies for general populations in which most new IDDM arises (35), and to classify etiology in new-onset patients, as shown here. 
Table II. Relationship of the Islet Cell Antibody Test to the GAD65Ab Test

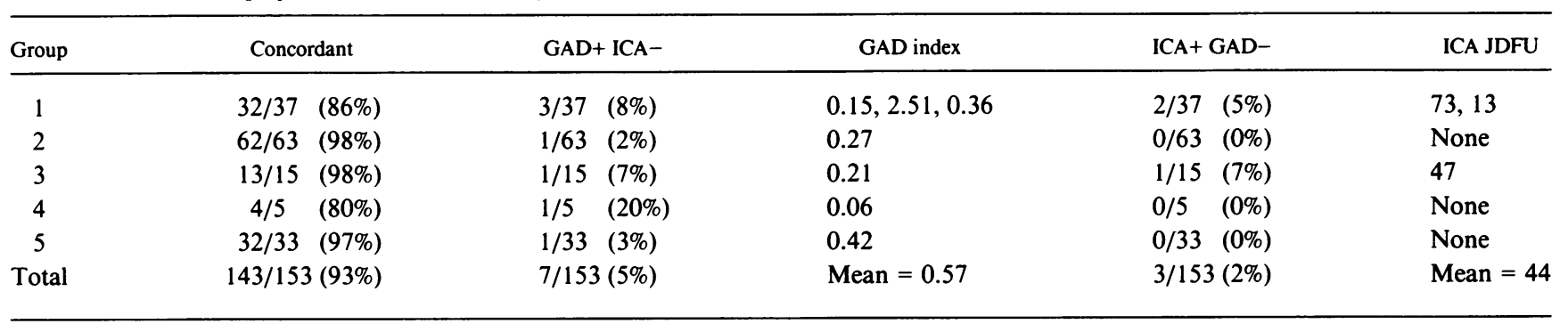

For those positive for GAD65Ab alone, or for ICA alone, quantitative indices or titers, respectively, are shown.

Recombinant GAD65, cloned from human islets and expressed in hamster fibroblasts, is well recognized by diabetic autoantibodies. Expression of recombinant antigen in mammalian cells (versus in vitro expression or expression in bacterial hosts) may allow posttranslational processing more similar to that occurring in beta cells, and thereby increase assay sensitivity. Positivity in new-onset diabetic sera using islet-derived $64 \mathrm{~K}$ antigen in immunoprecipitation assays has ranged from 71 to $89 \%$, and is higher when using human rather than rat islets $(3,5,8,23)$ despite the $96 \%$ amino acid sequence homology between GAD65 of the two species (36). However, results from our laboratory suggest that the nascent polypeptide produced by in vitro transcription and translation of the human islet GAD2 gene is precipitated by 75\% of new-onset IDDM sera (37). These similar percentages suggest that most antigenic epitopes of GAD65 are in the primary, secondary, and tertiary structure of the protein itself, rather than at sites created after cellular translation.

In this study and previously, we and others have observed remarkable persistence of $64 \mathrm{~K}$ antibody and GAD65Ab levels for up to $5 \mathrm{yr}$ after onset (38-40). This is distinct from the often transient ICA positivity $(29,38)$. Whether neuronal GAD, antigen mimicry from persistent viral infection, or a lingering few endocrine cells provide antigen to sustain autoantibody production remains to be investigated, although plasma C-peptide after onset (from remaining beta cells) does not correlate with GAD65Ab persistence (40).

GAD65Ab probably contributes to ICA assay positivity. This assay, using immunofluorescence of pancreatic tissue sections to detect anti-islet antibodies, is time consuming, suffers from lack of availability of human pancreatic substrate, and is difficult to standardize as emphasized by the latest international workshop (21). In comparison, this GAD65Ab assay uses standardized reagents and has future potential for high efficiency and rapidity. While current inter- and intra-assay coefficients of variation are $>20 \%$, these compare favorably with the twofold dilutions used to generate ICA titers (steps of $50 \%$ in antibody quantitation). Fig. $4 C$ and Table II suggest that antigens other than GAD65 also contribute to ICA positivity. Others have also found disparity between ICA and GAD autoantibody markers (41) and evidence for multiple ICA antigens (24-26). The ICA assay may provide predictive information distinct from GAD65Ab. Efforts to identify, clone, and express other ICA antigens may provide useful adjuncts to GAD65Ab not dependent on tissue-based methods.

Efficient tests screening for autoantibodies to multiple defined islet antigens, along with PCR-based HLA typing, may increase predictive value to identify high-risk individuals from the general population for beta cell function testing and im- munointervention. The higher prevalence of islet autoimmunity in new-onset NIDDM versus that in the general population gives GAD65Ab a high positive predictive value in these patients, who are also excellent candidates for immunointervention. We find here that patients presenting with maturityonset diabetes are, like relatives of IDDM patients, a high risk group for IDDM. GAD65Ab can reveal this IDDM within NIDDM.

\section{Acknowledgments}

We thank Charles Sauvageau, Seth McGrew, Ann Radelius, and Christina Rosborn for excellent technical assistance, Chris Marsh and James Perkins for human pancreas procurement, and David Stenger for helpful comments. W. A. Hagopian was supported by a McAbee Diabetes Fellowship and a Howard Hughes Medical Institute Fellowship for Physicians, A. E. Karlsen by JDF International, and J. S. Petersen by the Danish Research Academy. Islet isolation was supported by the Landsdowne Diabetes Research Endowment. GAD-6 hybridomas were from the Developmental Studies Hybridoma Bank, Iowa City, IA, National Institutes of Health grant HD-62915. BHK fibroblasts were from American Type Culture Collection, Bethesda, MD.

This work was supported by NIH grants DK-41801, DK-26190, DK-33873, and DK-42654, Diabetes Endocrinology Research Center grant DK-17047, Swedish Medical Research Council grant 07507, the Nordisk Foundation, and the Swedish Diabetes Association.

\section{References}

1. Lernmark, $\dot{A}$., and S. Baekkeskov. 1981. Islet cell antibodies: theoretical and practical implications. Diabetologia. 212:431-435.

2. Baekkeskov, S., J. H. Nielsen, B. Marner, T. Bilde, J. Ludvigsson, and Å. Lernmark. 1982. Autoantibodies in newly diagnosed diabetic children immunoprecipitate human pancreatic islet cell proteins. Nature (Lond.). 298:167-169.

3. Atkinson, M. A., N. K. Maclaren, D. W. Scharp, P. E. Lacy, and W. J. Riley. 1990. 64,000 Mr autoantibodies as predictors of insulin-dependent diabetes. Lancet. 335:1357-1360.

4. Bärmeier, H., D. K. McCulloch, J. L. Neifing, G. Warnock, R. V. Rajotte, J. P. Palmer, and L. A. 1991. Risk for developing type 1 (insulin-dependent) diabetes mellitus and the presence of islet 64K antibodies. Diabetologia. 34:727733.

5. Baekkeskov, S., M. Landin-Olsson, J. K. Kristensen, S. Srikanta, G. J. Bruining, T. Mandrup-Poulsen, C. de Beaufort, J. S. Soeldner, G. Eisenbarth, F. Lindgren, G. Sundkvist, and A. Lernmark. 1987. Antibodies to a Mr 64,000 human islet cell antigen precede the clinical onset of insulin-dependent diabetes. J. Clin. Invest. 79:926-934.

6. Baekkeskov, S., T. Dyrberg, and Å. Lernmark. 1984. Autoantibodies to a 64-kilodalton islet cell protein precede the onset of spontaneous diabetes in the BB rat. Science (Wash. DC). 224:1348-1350.

7. Atkinson, M. A., and N. K. Maclaren. 1988. Autoantibodies in nonobese diabetic mice immunoprecipitate $64,000-\mathrm{Mr}$ islet antigen. Diabetes. 37:15871590.

8. Christie, M., M. Landin-Olsson, G. Sundkvist, G. Dahlquist, Ả. Lernmark, and S. Baekkeskov. 1988. Antibodies to a Mr 64,000 islet cell protein in Swedish 
children with newly diagnosed type 1 (insulin-dependent) diabetes. Diabetologia. 31:597-602.

9. Baekkeskov, S., H. J. Aanstoot, S. Christgau, A. Reetz, M. Solimena, M. Cascalho, F. Folli, H. Richter-Olesen, and P. De Camilli. 1990. Identification of the $64 \mathrm{~K}$ autoantigen in insulin-dependent diabetes as the GABA-synthesizing enzyme glutamic acid decarboxylase. Nature (Lond.). 347:151-156.

10. Karlsen, A. E., B. K. Michaelsen, J. K. Pedersen, W. A. Hagopian, C. E. Grubin, E. Boel, O. Madsen, D. P. Stenger, and Å. Lernmark. 1992. Glutamic acid decarboxylase: an autoantigenin insulin-dependent diabetes mellitus. Diabetes Nutr. Metab. In press.

11. Erlander, M., and A. Tobin. 1991. The structural and functional heterogeneity of glutamic acid decarboxylase: a review. Neurochem. Res. 16:215-226.

12. Michelsen, B. K., J. S. Petersen, E. Boel, A. Møldrup, T. Dyrberg, and O. D. Madsen. 1991. Cloning, characterization, and autoimmune recognition of rat islet glutamic acid decarboxylase in insulin-dependent mellitus. Proc. Natl. Acad. Sci. USA. 88:8754-8758.

13. Christgau, S., H. Schierbeck, H.-J. Aanstoot, L. Aagaard, K. Begley, H. Kofod, K. Hejnaes, and S. Baekkeskov. 1991. Pancreatic $\beta$ cells express two autoantigenic forms of glutamic acid decarboxylase, a 65-kDa hydrophilic form and a 64-kDa amphiphilic form which can be both membrane-bound and soluble. J. Biol. Chem. 286:21257-21264.

14. Karisen, A. E., W. A. Hagopian, C. E. Grubin, S. Dube, C. M. Disteche, D. A. Adler, H. Bärmeier, S. Mathewes, F. J. Grant, D. Foster, and Å. Lernmark. 1991. Cloning and primary structure of a human islet isoform of glutamic acid decarboxylase from chromosome 10. Proc. Natl. Acad. Sci. USA. 88:8337-8341.

15. Karlsen, A. E., W. A. Hagopian, J. S. Petersen, E. Boel, T. Dyrberg, C. E. Grubin, B. Michelsen, O. D. Madsen, and A. Lernmark. 1992. Recombinant glutamic acid decarboxylase representing the single isoform expressed in human islets detects IDDM associated $64 \mathrm{~K}$ autoantibodies. Diabetes. In press.

16. Talavera, A., and C. Basilico. 1977. Temperature sensitive mutants in BHK cells affected in cell cycle progression. J. Cell Physiol. 92:425-436.

17. Busby, S. J., E. Mulvihill, D. Rao, A. A. Kumar, P. Lioubin, M. Heipel, C. Sprecher, L. Halfpap, D. Prunkard, J. Gambee, and D. C. Foster. 1991. Expression of recombinant human plasminogen in mammalian cells is augmented by suppression of plasmin activity. J. Biol. Chem. 266:15286-15292.

18. Gottlieb, D. I., Y.-C. Chang, and J. E. Schwob. 1986. Monoclonal antibodies to glutamic acid decarboxylase. Proc. Natl. Acad. Sci. USA. 83:8808-8812.

19. Hagopian, W. A., S. Dube, A. E. Karlsen, C. Grubin, and Å. Lernmark. 1991. Analysis of glutamic acid decarboxylase shows autoantigen hetrogeneity in dog and human islets. Diabetologia. 34:97.

20. Landin-Olsson, M., K. O. Nilsson, Ȧ. Lernmark, and G. Sundkvist. 1990. Islet cell antibodies and fasting $\mathrm{C}$-peptide predict insulin requirement at diagnosis of diabetes mellitus. Diabetologia. 33:561-568.

21. Lernmark, A., J. L. Molenaar, W. A. M. vanBeers, Y. Yamaguchi, S. Nagataki, J. Ludvigsson, and N. K. Maclaren. 1991. The Fourth International Serum Exchange Workshop to standardize cytoplasmic islet cell antibodies. Diabetologia. 34:534-535.

22. Pipeleers, D. 1987. Biosociology of pancreatic B cells. Diabetologia. 30:277-291.

23. Christie, M. R., G. Vohra, P. Champagne, D. Daneman, and T. L. Delovitch. 1990. Distinct antibody specificities to a 64-kD islet cell antigen in type 1 diabetes as revealed by trypsin treatment. J. Exp. Med. 172:789-794.

24. Gianani, R., A. Pugliese, S. Bonner-Weir, A. J. Shiffrin, J. S. Soeldner, H. Erlich, Z. Awdeh, C. Alper, R. Jackson, and G. S. Eisenbarth. 1992. Prognostically significant heterogeneity of cytoplasmic islet cell antibodies in relatives of patients with IDDM. Diabetes. 41:347-353.

25. Gillard, A. K., J. W. Thomas, L. J. Nell, and D. M. Marcus. 1989. Antibod- ies against ganglioside GT3 in the sera of patients with type 1 diabetes mellitus. $J$. Immunol. 142:3826-3832.

26. Karounos, D. G., L. J. Nell, and J. W. Thomas. 1990. Autoantibodies present at onset of type 1 diabetes recognize multiple islet cell antigens. Autoimmun. 6:79-91.

27. Dahlquist, G., L. Blom, T. Tuvemo, L. Nyström, A. Sandström, and S. Wall. 1989. The Swedish childhood diabetes study: results from a nine year case register and one year case-referent study indicating that type 1 (insulin-dependent) diabetes mellitus is associated with both type 2 (non-insulin-dependent) diabetes mellitus and autoimmune disorders. Diabetologia. 32:2-6.

28. Porte, D. J. 1991. $\beta$-cells in type II diabetes mellitus. Diabetes. 40:166180.

29. Kobayashi, T., T. Itoh, K. Kasaka, K. Sato, and K. Tsuji. 1987. Time course of islet cell antibodies and $\beta$-cell function in non-insulin-dependent stage of type 1 diabetes. Diabetes. 36:510-517.

30. Arner, P., T. Pollare, and H. Lithell. 1991. Different etiologies of type 2 (non-insulin-dependent) diabetes mellitus in obese and non-obese subjects. Diabetologia. 34:483-487.

31. Madsbad, S., T. Krarup, P. McNair et al. 1981. Practical clinical value of the C-peptide response to glucagon stimulation in the choice of treatment in diabetes mellitus. Acta Med. Scand. 210:153-156.

32. Nakanishi, K., T. Kobayashi, T. Sugimoto, T. Murase, and T. Itoh. 1988. Predictive value of insulin autoantibodies for further progression of beta cell dysfunction in non-insulin dependent diabetics. Diabetes Res. Clin. Pract. 9:105109.

33. Gottsäter, A., U. Samuelsson, S. Nilsson, Å. Lernmark, and G. Sundkvist. 1992. Islet cell antibodies and fasting plasma C-peptide during the first 10 years after diagnosis in patients with adult-onset diabetes mellitus. Diabetes Nutr. $\mathrm{Me}$ tab. In press.

34. Nyström, L., J. Ostman, S. Wall, and L. Wibell. 1992. Mortality of all incident cases of diabetes mellitus diagnosed 1983-1987 at age 15-34 years: diabetes incidence study in Sweden (DISS) group. Diabet. Med. 9:422-427.

35. Rewers, M. 1991. The changing face of the epedemiology of insulin-dependent diabetes mellitus (IDDM): research designs and models of disease causation. Ann. Med. 23:419-426.

36. Bu, D.-F., M. G. Erlander, B. C. Hitz, N. J. Tillakaratne, D. L. Kaufman, C. B. Wagner-McPherson, and G. A. Evans. 1992. Two human glutamate decarboxylases, 65-kDA GAD and 67-kDa GAD, are each encoded by a single gene. Proc. Natl. Acad. Sci. USA. 89:2115-2119.

37. Grubin, C., T. Daniels, A. E. Karlsen, E. Boel, W. A. Hagopian, and Å. Lernmark. 1992. The cDNA-directed, in vitro-synthesized nascent peptide of glutamic acid decarboxylase (GAD2) is the autoantigen in insulin-dependent diabetes. Clin. Res. 40:299A. (Abstr.)

38. Christie, M., and T. L. Delovitch. 1990. Persistence of antibodies to a 64,000-Mr islet cell protein after onset of type 1 diabetes. Diabetes. 39:653-659.

39. Bärmeier, H., S. Ivarsson, B. Lindberg, M. Landin-Olsson, G. Sundkvist, R. Rajotte, G. Warnock, and $\AA$. Lernmark. 1991. High titer $64 \mathrm{~K}$ antibodies in 5-year follow-up study of type I diabetic children. Diabetologia. 34:A98. (Abstr.)

40. Hagopian, W. A., A. E. Karlsen, A. Gottsäter, M. Landin-Olsson, G. Sundkvist, C. Grubin, E. Boel, T. Dyrberg, and Å. Lernmark. 1992. Human islet glutamic acid decarboxylase autoantibody levels persist up to 5 years after onset and are unaffected by plasmapheresis in type I diabetes. Diabetologia. 35:A209. (Abstr.)

41. Kaufman, D. J., M. G. Erlander, M. Clare-Salzer, M. A. Atkinson, N. K. Maclaren, and A. J. Tobin. 1992. Autoimmunity to two forms of glutamate decarboxylase in insulin-dependent diabetes mellitus. J. Clin. Invest. 89:283292. 